www.jmscr.igmpublication.org

Impact Factor 5.84

Index Copernicus Value: 83.27

ISSN (e)-2347-176x ISSN (p) 2455-0450

crossref DOI:_https://dx.doi.org/10.18535/jmscr/v5i3.43

Journal Of Medical Science And Clinical Research

IGM Publication

An Official Publication of IGM Publication

\title{
Correlation between End-Tidal Carbon Dioxide Pressure and Arterial Carbon Dioxide Partial Pressure in Patients Undergoing Craniotomy
}

\author{
Authors \\ Dr Meena M.Pimpare ${ }^{1}$, Dr Devanand B. Deosarkar ${ }^{2}$ \\ ${ }^{1}$ Assistant Professor, ${ }^{2}$ Senior Resident \\ Dept of Anesthesiology, Dr Shankarrao Chavan Govt Medical College and Hospital, Vishnupuri, Nanded \\ Corresponding Author \\ Dr Meena M.Pimpare \\ Assistant Professor, Dr Shankarrao Chavan Govt Medical College and Hospital,Vishnupuri, Nanded
}

\begin{abstract}
Background: End-tidal carbon dioxide pressure (ETCO2) is commonly used as an indicator of arterial partial pressure of carbon dioxide ( $\mathrm{PaCO} 2)$ which reflects adequacy of ventilation during major surgeries. While accurate determination of PaCO2 level is an important aspect of anesthetic management of the patient it is all the way more important in neurosurgeries where changes in PaCO2 can have a profound effect on cerebral blood flow. Moreover practice of reducing intracranial pressure by means of hyperventilation is often used to reduce intracranial pressure in neurosurgical patients. There has also been some controversy in recent anesthetic literature about whether end tidalCO2 (ETCO2) is an accurate reflection of PaCO2. This study was aimed to evaluate the relationship between ETCO2 and arterial PaCO2 in neurosurgical patients undergoing craniotomy and to assess the predictive value of ETCO2 as an indicator of PaCO2 level. Aims and Objectives:

1. To study the correlation in between arterial to end tidal CO2 in neurosurgical patients undergoing craniotomy.

1. To study the correlation in between arterial to end tidal CO2 in neurosurgical patients undergoing craniotomy.

Materials and Methods: This was a prospective study conducted on 30 patients aged between 18 to 60 years who were posted for elective craniotomy under general anaesthesia at a major hospital in an urban area. The patients were included in the study after approval of the institutional ethical committee and written informed valid consent obtained from the patient. Patients were taken to operation theatre and routine pre anesthetic examination was done. Vitals were noted. All patients were anaesthetized using standard balanced general anaesthesia as per attending anesthesiologist and set protocol for neurosurgery cases. PaCO2 and PETCO2 were recorded immediately after induction followed by every hourly till end of surgery. Data was collected and statistical analysis was done with the help of SPSS Software version 15.

Results: Total 30 patients were studied. Out of these cases 18 were males and 12 were females with a maleto female ratio being 1: 0.66. The analysis of age group of the patients revealed that majority (36.66\%) of the patients belonged to age group of 31-40 years. The percentage of patients in the age group of 21-30 years and 41-50 years was similar (20\%). 12 (40\%) patients belonged to ASA I category and 18 (60\%) patients belonged to ASA II category. There was no patient belonging to other ASA categories as belonging to ASA I or ASA II category was the inclusion criteria of our study. Most common indication for surgery was meaningioma which was seen in 15 (50\%) patients followed by glioma, Cerebellopontine angle tumor,
\end{abstract}




\section{JMSCR Vol||05||Issue||03||Page 18525-18533||March}

schwannoma and glioblastoma which was seen in 6 (20\%), 4 (13.33\%), 3 (10\%) and 2 (7.66\%) patients respectively. All surgeries were uneventful. The analysis of $\mathrm{PaCO} 2$ and ETCO2 with respective to mean and standard deviations of pulse rate, Mean arterial pressure and central venous pressure during surgeries showed stable pulse rate, MAP and CVP throughout the surgical procedures thereby ruling out the fluctuations of these parameters as a cause of changes in PaCO2 and ETCO2. The data was analyzed for correlation between PaCO2 and ETCO2 at different intervals during craniotomy. Statistically significant correlation was found between PaCO2 and ETCO2 at baseline, $1 \mathrm{hr}, 2 \mathrm{hr}, 3 \mathrm{hr}$ and $4 \mathrm{hrduring}$ surgery.

Conclusion: In Our study there was a statistically significant correlation between PaCO2 and ETCO2 during elective neurosurgery patients undergoing craniotomy under general anaesthesia. Our study concludes that end-tidal CO2 (ETCO2) reflects arterial CO2 with acceptable accuracy and hence capnometry can be relied upon as a reflection of arterial PaCO2 in neurosurgical patients undergoing craniotomy.

Keywords: End tidal Co2, PaCO2, capnometry, Craniotomy.

\section{Introduction}

In neurosurgery and neuroanaesthesia, continuous monitoring of $\mathrm{ETCO}_{2}$ and intermittent monitoring of $\mathrm{PaCO}_{2}$ is standard set protocol. Both $\mathrm{PaCO}_{2}$ and $\mathrm{ETCO}_{2}$ are indicators of ventilatory adequacy. It is important to know the $\mathrm{PaCO}_{2}$ in neuroanaesthesia because of its effect on cerebral blood flow. $\mathrm{ETCO}_{2}$ has been used as non-invasive estimate of $\mathrm{PaCO}_{2}{ }^{[1]}$.

1. The usual reported difference between $\mathrm{PaCO}_{2}$ and $\mathrm{ETCO}_{2}$ in healthy awake patients is 3.6 to $4.6 \mathrm{~mm}$ of $\mathrm{Hg}^{[2]}$.

2. A significant variability has been observed in mechanically ventilated neurosurgical ICU patients and in patients undergoing craniotomy in different positions ${ }^{[3]}$.

3. There has also been some controversy in recent anaesthetic literature whether end tidal $\mathrm{CO}_{2}\left(\mathrm{ETCO}_{2}\right)$ is an accurate reflection of $\mathrm{PaCO}_{2}{ }^{[4]}$.

Capnography is an accepted standard of care for intraoperative monitoring of mechanically ventilated patients and is often used during ventilation of critically ill patients with respiratory failure ${ }^{[5]}$. The respiratory rate, $\mathrm{PETCO}_{2}$, and the respiratory waveform morphology are used to assess the presence of respiratory distress, ventilatory adequacy, and bronchial obstruction. $\mathrm{ETCO}_{2}$ is used clinically as a positive indicator of endotracheal intubation, a disconnected alarm, and an estimation of $\mathrm{PaCO}_{2}$. Capnography, which is based on the measurement of end tidal carbon dioxide $\left(\mathrm{ETCO}_{2}\right)$, is a well-established method for intraoperative monitoring of respiratory function during routine anaesthesia ${ }^{[6] .} \mathrm{ETCO}_{2}$ refers to the partial pressure of carbon dioxide at the end of expiration and reflects arterial carbon dioxide tension $\left(\mathrm{PaCO}_{2}\right)$. One of the treatment modality used by anesthesiologist for the management of raised intracranial pressure (ICP) in neurosurgical patients is hyperventilation, which reduces arterial $\mathrm{PaCO}_{2}$ and hyperventilation is only effective when the $\mathrm{PaCO}_{2}$ reactivity of cerebral vasculature is normal and intact ${ }^{[7]}$. It is well known that $\mathrm{PaCO}_{2}$ correlates inversely with cerebral arterial resistance ${ }^{[8]}$. Therefore, it is important that an anaesthesiologist must be aware of $\mathrm{PaCO}_{2}$ and $\mathrm{ETCO}_{2}$ values during procedures where raised ICP is a potential problem ${ }^{[9]}$. Other methods to reduce raised intracranial pressure are - CSF drainage, ventriculostomy, diuresis (mannitol), cerebral metabolic rate compression (barbiturates, propofol), mean arterial pressure reduction (if dysautoregulation) and surgical control ${ }^{[10,11]}$.

This study is undertaken to review our routine practice of obtaining $\mathrm{PaCO}_{2}$ during craniotomy procedures and comparing it with the $\mathrm{ETCO}_{2}$ at the same time. The objective is to see whether $\mathrm{ETCO}_{2}$ reflected the $\mathrm{PaCO}_{2}$ with acceptable accuracy.

\section{Materials and Methods}

After approval of the institutional ethics committee and written informed valid consent 
obtained from the patient, 30 patients aged between 18 to 60 years who were posted for elective craniotomy under general anaesthesia at our hospital was chosen.

\section{Inclusion Criteria:}

1. Age18 to 60 yrs.

2. Patients belonging to ASA I and II.

3. Elective craniotomies in supine and sitting position.

4. Patients who are conscious and oriented with time, place and person.

5. Duration of surgery 4-5 hrs.

\section{Exclusion Criteria}

1. Patients age $<18$ yrs and $>60$ yrs.

2. Preoperatively intubated patients.

3. Patients with bleeding diathesis.

4. Patients with coexisting chronic bronchopulmonary disease and severe hemodynamic instability.

5. Intraoperative venous air embolism.

6. Patient's refusal.

This was a prospective study. All patients were anaesthetized using standard balanced general anaesthesia as per attending anesthesiologist and set protocol for neurosurgery cases.

Post induction arterial line was taken in all patients by cannulating radial artery (most commonly) as per the standard set protocol in all neurosurgery cases.

After patient positioning and achieving hemodynamic stability a baseline arterial blood sample was collected and $\mathrm{PaCO}_{2}$ was measured by using blood gas analyzer and corrected to a temperature of $37^{\circ}$ Celsius, simultaneously $\mathrm{PETCO}_{2}$ also recorded by using a side-stream capnometer which was connected by angle piece connector in between endotracheal tube and breathing circuit.

The first post induction measurement was taken as a baseline and then repeated every 1 hourly until the end of surgery. Simultaneous measurement of blood pressure, heart rate, respiratory rate, central venous pressure, tidal volume, inspired $\mathrm{O}_{2}$ fraction $\left(\mathrm{FiO}_{2}\right)$, peak inspiratory pressure were recorded at each sampling time. All the other hemodynamic and respiratory parameters were recorded at the same time at the timing of collection of arterial sample for $\mathrm{PaCO}_{2}$ and recording of $\mathrm{ETCO}_{2}$ from capnometer from the same patient so that the values of $\mathrm{PaCO}_{2}$ and $\mathrm{ETCO}_{2}$ are not influenced by these parameters during respective intervals of collection of data throughout the surgical procedure. Data was collected and statistical analysis was done with the help of SPSS Software version 15.

\section{Results}

Overall 30 patients were studied in the age group of 18 to 60 years, $60 \%$ patients were male and $40 \%$ patients female (Figure 1 ).

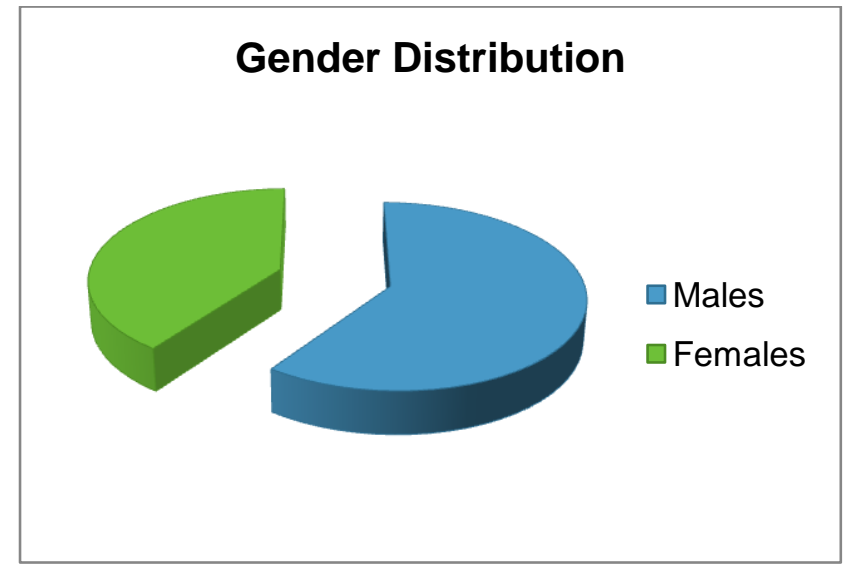

Figure 1: Gender distribution of the studied cases. In our study total 30 patients were studied from 18-60 years. These were distributed in different groups according to number of patients, out of these youngest patient was 23 years old and oldest was 59 years (Table 1).

Table 1: Age distribution of the studied cases

\begin{tabular}{|lc|}
\hline Age Group & Percentage of patients \\
\hline $\mathbf{2 1 - 3 0}$ & $20 \%$ \\
\hline $\mathbf{3 1 - 4 0}$ & $36.66 \%$ \\
\hline $\mathbf{4 1 - 5 0}$ & $20 \%$ \\
\hline $\mathbf{5 1 - 6 0}$ & $23.33 \%$ \\
\hline
\end{tabular}

Out of total patients $40 \%$ belongs to ASA I category and 60\% belongs to ASA II category.

All 30 patients involved in the study have undergone elective craniotomy for various 
diagnoses as mentioned in the table and as given bellow (Table 2).

Table 2: Indication for craniotomy in studied cases

\begin{tabular}{|l|c|c|}
\hline Diagnosis & Frequency & Percent \\
\hline CP Angle Tumour & 4 & $13.33 \%$ \\
\hline Glioblastoma & 2 & $7.66 \%$ \\
\hline Glioma & 6 & $20.00 \%$ \\
\hline Meningioma & 15 & $50.00 \%$ \\
\hline Schwannoma & 3 & $10.00 \%$ \\
\hline Total & 30 & $100 \%$ \\
\hline
\end{tabular}

During study, all surgical procedures were uneventful. Throughout surgical procedure standard cardiorespiratory monitoring was done. All the standard cardiorespiratory parameters such as Heart rate, Blood pressure, Mean arterial pressure, Central venous pressure, Respiratory rate, $\mathrm{PaCO}_{2}$ and $\mathrm{PETCO}_{2}$ recorded at regular interval of 1 hour after baseline sample. All the cardiorespiratory parameters were within normal limit [Table 3].

Table 3: Study parameters (Cardiorespiratory variables) during surgical procedure.

\begin{tabular}{|c|c|c|c|c|c|c|c|}
\hline Study Parameter & $\mathrm{N}$ & Mean & Std. Dev & Median & IQR & Minimum & Maximum \\
\hline $\mathrm{PaCO} 2 \mathrm{BL}$ & 30 & 37.13 & 1.85 & 37.60 & 1.78 & 32.80 & 39.80 \\
\hline $\mathrm{PaCO} 2 \mathrm{After} 1 \mathrm{hr}$ & 30 & 36.74 & 1.49 & 36.80 & 2.37 & 34.50 & 39.90 \\
\hline PaCO2 After 2hr & 30 & 36.49 & 1.61 & 36.80 & 1.68 & 32.10 & 38.90 \\
\hline $\mathrm{PaCO} 2$ After $3 \mathrm{hr}$ & 30 & 36.62 & 1.55 & 36.60 & 2.90 & 33.80 & 39.70 \\
\hline PaCO2 After 4hr & 30 & 36.61 & 1.81 & 36.80 & 2.45 & 32.70 & 39.90 \\
\hline EtCO2 BL & 30 & 33.47 & 1.78 & 34.00 & 3.00 & 29.00 & 37.00 \\
\hline EtCO2 After $1 \mathrm{hr}$ & 30 & 33.53 & 1.07 & 34.00 & 1.25 & 32.00 & 35.00 \\
\hline EtCO2 After $2 \mathrm{hr}$ & 30 & 33.23 & 1.17 & 33.00 & 1.25 & 31.00 & 36.00 \\
\hline EtCO2 After $3 \mathrm{hr}$ & 30 & 33.10 & 1.21 & 33.00 & 2.00 & 31.00 & 35.00 \\
\hline EtCO2 After $4 \mathrm{hr}$ & 30 & 33.43 & 1.96 & 34.00 & 2.00 & 30.00 & 38.00 \\
\hline $\mathrm{P}(\mathrm{a}-\mathrm{E} \mathrm{t}) \mathrm{CO} 2 \mathrm{BL}$ & 30 & 3.66 & 1.15 & 3.55 & 1.23 & 1.50 & 6.80 \\
\hline $\mathrm{P}(\mathrm{a}-\mathrm{Et}) \mathrm{CO} 2 \mathrm{After} 1 \mathrm{hr}$ & 30 & 3.20 & 1.31 & 3.65 & 1.43 & -0.40 & 5.60 \\
\hline $\mathrm{P}(\mathrm{a}-\mathrm{Et}) \mathrm{CO} 2 \mathrm{After} 2 \mathrm{hr}$ & 30 & 3.26 & 1.73 & 3.75 & 1.33 & -1.40 & 6.60 \\
\hline $\mathrm{P}(\mathrm{a}-\mathrm{Et}) \mathrm{CO} 2 \mathrm{After} 3 \mathrm{hr}$ & 30 & 3.52 & 1.49 & 3.80 & 1.95 & 0.60 & 5.80 \\
\hline $\mathrm{P}(\mathrm{a}-\mathrm{Et}) \mathrm{CO} 2 \mathrm{After} 4 \mathrm{hr}$ & 30 & 3.18 & 1.80 & 3.20 & 1.65 & -0.30 & 8.10 \\
\hline PR BL & 30 & 81.00 & 3.51 & 82.00 & 6.00 & 74.00 & 86.00 \\
\hline PR After $1 \mathrm{hr}$ & 30 & 79.80 & 3.76 & 82.00 & 6.00 & 74.00 & 86.00 \\
\hline PR After $2 \mathrm{hr}$ & 30 & 78.73 & 3.26 & 78.00 & 1.50 & 74.00 & 86.00 \\
\hline PR After $3 \mathrm{hr}$ & 30 & 76.13 & 3.32 & 76.00 & 4.00 & 70.00 & 82.00 \\
\hline PR After $4 \mathrm{hr}$ & 30 & 78.20 & 4.53 & 79.00 & 6.00 & 68.00 & 84.00 \\
\hline RR BL & 30 & 12.00 & 0.00 & 12.00 & 0.00 & 12.00 & 12.00 \\
\hline RR After $1 \mathrm{hr}$ & 30 & 12.00 & 0.00 & 12.00 & 0.00 & 12.00 & 12.00 \\
\hline RR After $2 \mathrm{hr}$ & 30 & 12.00 & 0.00 & 12.00 & 0.00 & 12.00 & 12.00 \\
\hline RR After $3 \mathrm{hr}$ & 30 & 12.00 & 0.00 & 12.00 & 0.00 & 12.00 & 12.00 \\
\hline RR After $4 \mathrm{hr}$ & 30 & 12.00 & 0.00 & 12.00 & 0.00 & 12.00 & 12.00 \\
\hline SBP $(m m H g) B L$ & 30 & 128.87 & 3.85 & 128.00 & 6.00 & 120.00 & 138.00 \\
\hline DBP $(\mathrm{mmHg})$ After $1 \mathrm{hr}$ & 30 & 71.20 & 5.57 & 70.00 & 6.00 & 62.00 & 82.00 \\
\hline SBP $(\mathrm{mmHg})$ After $2 \mathrm{hr}$ & 30 & 125.67 & 2.47 & 126.00 & 4.00 & 120.00 & 132.00 \\
\hline DBP $(\mathrm{mmHg})$ After $3 \mathrm{hr}$ & 30 & 70.33 & 4.64 & 70.00 & 6.00 & 64.00 & 80.00 \\
\hline SBP $(\mathrm{mmHg})$ After $4 \mathrm{hr}$ & 30 & 126.47 & 2.96 & 126.00 & 4.00 & 120.00 & 132.00 \\
\hline $\mathrm{DBP}(\mathrm{mmHg}) \mathrm{BL}$ & 30 & 68.93 & 4.92 & 69.00 & 8.50 & 60.00 & 80.00 \\
\hline SBP $(\mathrm{mmHg})$ After $1 \mathrm{hr}$ & 30 & 125.47 & 2.87 & 126.00 & 6.00 & 120.00 & 130.00 \\
\hline DBP $(\mathrm{mmHg})$ After $2 \mathrm{hr}$ & 30 & 68.53 & 4.23 & 68.00 & 6.00 & 64.00 & 78.00 \\
\hline SBP $(\mathrm{mmHg})$ After $3 \mathrm{hr}$ & 30 & 126.20 & 3.21 & 126.00 & 4.00 & 122.00 & 134.00 \\
\hline DBP $(\mathrm{mmHg})$ After $4 \mathrm{hr}$ & 30 & 68.27 & 4.69 & 68.00 & 6.00 & 60.00 & 80.00 \\
\hline MAP $(\mathrm{mmHg}) \mathrm{BL}$ & 30 & 90.42 & 3.67 & 90.33 & 4.67 & 84.00 & 98.00 \\
\hline MAP $(\mathrm{mmHg})$ After $1 \mathrm{hr}$ & 30 & 88.78 & 2.93 & 88.33 & 4.00 & 84.67 & 95.33 \\
\hline MAP $(\mathrm{mmHg})$ After $2 \mathrm{hr}$ & 30 & 88.11 & 3.30 & 88.67 & 4.83 & 82.67 & 94.67 \\
\hline MAP $(\mathrm{mmHg})$ After $3 \mathrm{hr}$ & 30 & 87.51 & 2.97 & 86.33 & 3.50 & 82.67 & 94.67 \\
\hline MAP $(\mathrm{mmHg})$ After $4 \mathrm{hr}$ & 30 & 87.58 & 3.25 & 87.33 & 4.50 & 82.00 & 95.33 \\
\hline CVP $(\mathrm{mmHg}) \mathrm{BL}$ & 30 & 6.83 & 0.91 & 6.50 & 2.00 & 6.00 & 8.00 \\
\hline CVP $(\mathrm{mmHg})$ After $1 \mathrm{hr}$ & 30 & 7.13 & 0.90 & 7.00 & 2.00 & 6.00 & 8.00 \\
\hline CVP $(\mathrm{mmHg})$ After $2 \mathrm{hr}$ & 30 & 6.70 & 0.88 & 6.00 & 2.00 & 6.00 & 8.00 \\
\hline CVP $(\mathrm{mmHg})$ After $3 \mathrm{hr}$ & 30 & 7.23 & 0.77 & 7.00 & 1.00 & 6.00 & 8.00 \\
\hline CVP $(\mathrm{mmHg})$ After $4 \mathrm{hr}$ & 30 & 6.97 & 0.96 & 7.00 & 2.00 & 6.00 & 8.00 \\
\hline
\end{tabular}




\section{JMSCR Vol||05||Issue||03||Page 18525-18533||March}

Study of mean and standard deviations of Pulse rate monitoring during Craniotomy at regular intervals as respective with $\mathrm{PaCO}_{2}$ and $\mathrm{ETCO}_{2}$ measurements was studied. This showed stable pulse rate throughout the procedure and this does not influences the correlation between $\mathrm{PaCO}_{2}$ and $\mathrm{ETCO}_{2}$.

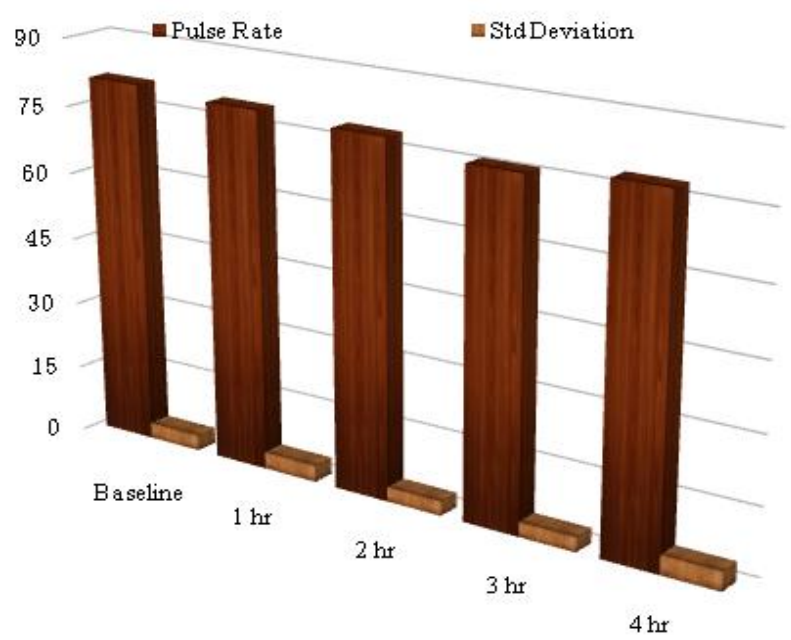

Figure 2: Pulse rate mean and standard deviations at regular intervals during craniotomy.

Below graph shows mean and standard deviations of Mean arterial pressure (MAP) monitoring during Craniotomy at regular intervals as respective with $\mathrm{PaCO}_{2}$ and $\mathrm{ETCO}_{2}$ measurements. This shows stable MAP throughout the procedure and this does not influence the correlation between $\mathrm{PaCO}_{2}$ and $\mathrm{ETCO}_{2}$ (Figure 3).

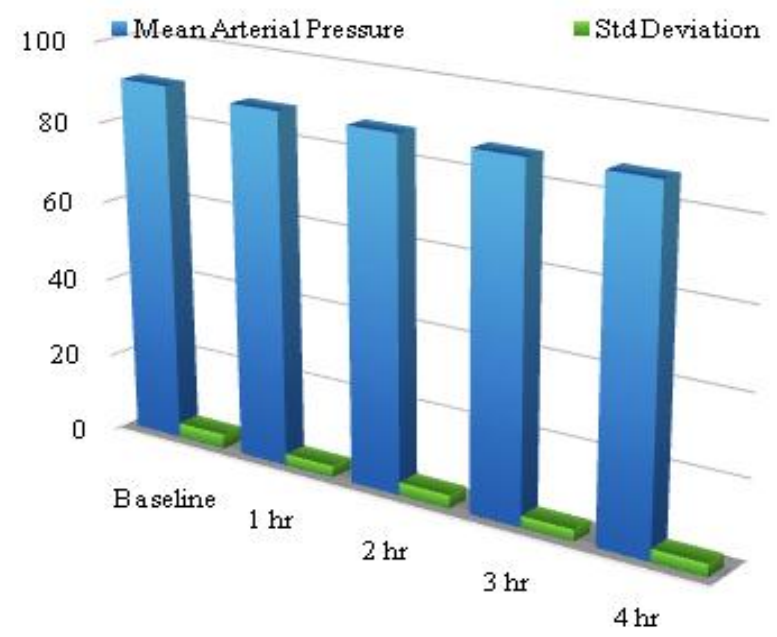

Figure 3: Mean arterial Pressures mean and standard deviations at regular intervals during craniotomy.
Graph below shows mean and standard deviations of Central venous pressure (CVP) monitoring during Craniotomy at regular intervals as respective with $\mathrm{PaCO}_{2}$ and $\mathrm{ETCO}_{2}$ measurements. This shows stable CVP throughout the procedure and this does not influences the correlation between $\mathrm{PaCO}_{2}$ and $\mathrm{ETCO}_{2}$

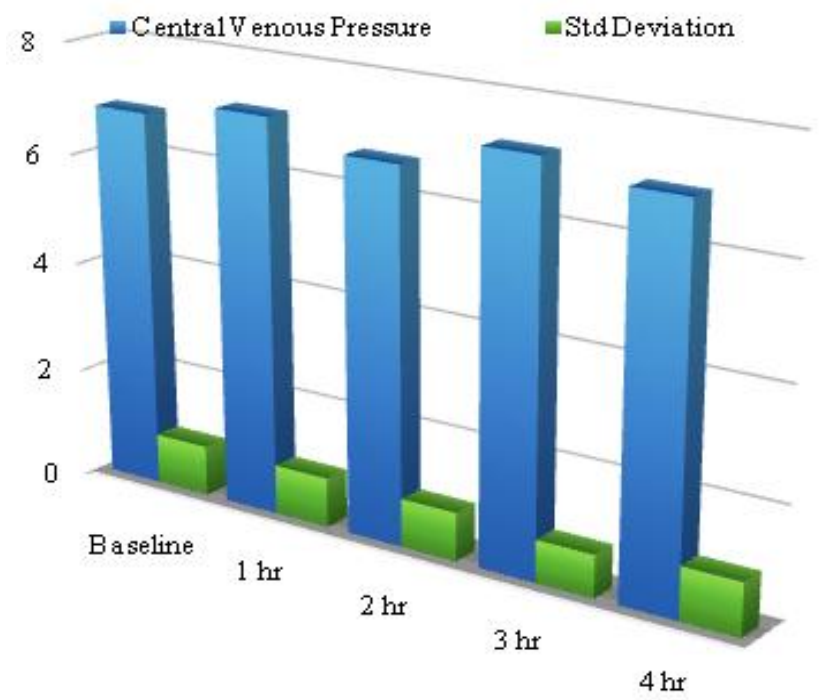

Figure 4 : Central Venous pressure mean and standard deviations at regular intervals during craniotomy.

The correlation between $\mathrm{PaCO} 2$ and ETCO 2 was studied at different intervals during craniotomy . Data was analyzed by using Pearson's correlation to see the relationship between $\mathrm{PaCO}_{2}$ and $\mathrm{ETCO}_{2}$ at regular interval during surgery such as baseline sample was obtained after induction of anaesthesia and achieving stable hemodynamics and after that after interval of $1 \mathrm{hr}, 2 \mathrm{hr}, 3 \mathrm{hr}$ and 4hr. A "P "value of $<0.05$ is considered as significant. Data shows statistically significant correlation between $\mathrm{PaCO}_{2}$ and $\mathrm{ETCO}_{2}$ at baseline, $1 \mathrm{hr}, 2 \mathrm{hr}, 3 \mathrm{hr}$ and $4 \mathrm{hr}$ during surgery with Pearson's correlation coefficients $0.799,0.522$, $0582,0.439$ and 0.547 respectively and " $p$ " values of $0.000,0.003,0.001,0.015$ and 0.002 respectively and all are $<0.05$ and hence significant. 


\section{JMSCR Vol||05||Issue||03||Page 18525-18533||March}

Table 4 : Correlation between $\mathrm{PaCO} 2$ and PETCO2 during Craniotomy:

\begin{tabular}{|l|l|l|l|l|l|l|}
\hline Correlations & & EtCO2 BL & $\begin{array}{l}\text { EtCO2 After } \\
1 \mathrm{hr}\end{array}$ & $\begin{array}{l}\text { EtCO2 After } \\
\text { 2hr }\end{array}$ & $\begin{array}{l}\text { EtCO2 } \\
\text { After 3hr }\end{array}$ & $\begin{array}{l}\text { EtCO2 } \\
\text { After 4hr }\end{array}$ \\
\hline PaCO2 BL & $\begin{array}{l}\text { Pearson } \\
\text { Correlation }\end{array}$ & 0.799 & 0.247 & -0.062 & 0.430 & 0.235 \\
\hline & P Value & 0.000 & 0.188 & 0.745 & 0.018 & 0.212 \\
\hline & $\begin{array}{l}\text { Correlation } \\
\text { is }\end{array}$ & Significant & 30.000 & 30.000 & 30.000 & 30.000 \\
\hline $\begin{array}{l}\text { PaCO2 } \\
\text { After 1hr }\end{array}$ & $\begin{array}{l}\text { Pearson } \\
\text { Correlation }\end{array}$ & 0.217 & 0.522 & 0.006 & -0.166 & -0.239 \\
\hline & P Value & 0.248 & 0.003 & 0.975 & 0.380 & 0.203 \\
\hline & $\begin{array}{l}\text { Correlation } \\
\text { is }\end{array}$ & 30.000 & Significant & 30.000 & 30.000 & 30.000 \\
\hline $\begin{array}{l}\text { PaCO2 } \\
\text { After 2hr }\end{array}$ & $\begin{array}{l}\text { Pearson } \\
\text { Correlation }\end{array}$ & -0.146 & -0.015 & 0.582 & 0.015 & 0.031 \\
\hline & P Value & 0.442 & 0.938 & 0.001 & 0.939 & 0.871 \\
\hline & $\begin{array}{l}\text { Correlation } \\
\text { is }\end{array}$ & 30.000 & 30.000 & Significant & 30.000 & 30.000 \\
\hline $\begin{array}{l}\text { PaCO2 } \\
\text { After 3hr }\end{array}$ & $\begin{array}{l}\text { Pearson } \\
\text { Correlation }\end{array}$ & 0.238 & 0.018 & 0.298 & 0.439 & 0.355 \\
\hline & P Value & 0.206 & 0.924 & 0.110 & 0.015 & 0.054 \\
\hline & $\begin{array}{l}\text { Correlation } \\
\text { is }\end{array}$ & 30.000 & 30.000 & 30.000 & Significant & 30.000 \\
\hline $\begin{array}{l}\text { PaCO2 } \\
\text { After 4hr }\end{array}$ & $\begin{array}{l}\text { Pearson } \\
\text { Correlation }\end{array}$ & -0.079 & -0.299 & 0.290 & 0.269 & 0.547 \\
\hline & P Value & 0.678 & 0.108 & 0.120 & 0.151 & 0.002 \\
\hline & $\begin{array}{l}\text { Correlation } \\
\text { is }\end{array}$ & 30.000 & 30.000 & 30.000 & 30.000 & Significant \\
\hline
\end{tabular}

\section{Discussion}

Ideally under stable physiologic conditions, with perfectly accurate monitoring gradient between Arterial to End-tidal Carbon dioxide P (a-ET) $\mathrm{CO}_{2}$ should be close to zero, that is $\mathrm{PaCO}_{2}$ values could be assumed precisely and repeatedly from $\mathrm{ETCO}_{2}$ value ${ }^{[12,13]}$. Arterial blood gas measurement of $\mathrm{PaCO}_{2}$ is the gold standard for monitoring changes in blood Carbon dioxide but it is invasive, expensive, and provides only intermittent measures of $\mathrm{PaCO}_{2}$ whereas $\mathrm{ETCO}_{2}$ provides continuous respiratory monitoring of changes in blood Carbon dioxide ${ }^{[14,15]}$.

This study was carried out in 30 patients in the age group of 18 to 60 years undergoing elective craniotomy. In this study we studied the correlation of $\mathrm{PaCO}_{2}$ and $\mathrm{ETCO}_{2}$ during elective craniotomy operations.

Demographic data: In our study there were 30 patients included out of that 18 male and 12 female patients with mean age of $39.83 \pm 10.95$ years. There is no significant correlation in demographic data and correlation between $\mathrm{PaCO}_{2}$ and $\mathrm{ETCO}_{2}$.

ASA grade: There were 12 patients belonging to ASA I grade and 18 patients belonging to ASA II. There is no significant correlation in ASA grading and correlation between $\mathrm{PaCO}_{2}$ and $\mathrm{ETCO}_{2}$.

Diagnosis: In our study elective craniotomy was carried out in patients having $\mathrm{C} \mathrm{P}$ angle tumour (13.33\%), Glioblastoma (7.66\%), Glioma (20\%), Meningioma (50\%) and Schwannoma (10\%). There is no significant correlation in diagnosis and correlation between $\mathrm{PaCO}_{2}$ and $\mathrm{ETCO}_{2}$.

Hemodynamic data: In our study hemodynamic parameters were measured with respective to the measurement timing of $\mathrm{PaCO}_{2}$ and $\mathrm{ETCO}_{2}$ at baseline, $1 \mathrm{hr}, 2 \mathrm{hr}, 3 \mathrm{hr}$ and $4 \mathrm{hr}$ till the end of surgery in all the 30 patients. Mean pulse rate $(\mathrm{PR})$ were $81 \pm 3.51,79.80 \pm 3.76,78.73 \pm 3.26$, $76.13 \pm 3.32$ and $78.20 \pm 4.53$ respectively. Mean 


\section{JMSCR Vol||05||Issue||03||Page 18525-18533||March}

MAP measurements were 90.42 \pm 3.67 , $88.78 \pm 2.93, \quad 88.11 \pm 3.30, \quad 87.51 \pm 2.97 \quad$ and 87.58 \pm 3.25 respectively. Mean CVP measurements were $6.83 \pm 0.91,7.13 \pm 0.90,6.70 \pm 0.88$, $7.23 \pm 0.77$ and $6.97 \pm 0.96$ respectively. There is no significant correlation between this hemodynamic parameters and correlation between $\mathrm{PaCO}_{2}$ and $\mathrm{ETCO}_{2}$.

Correlation between $\mathrm{PaCO}_{2}$ and $\mathrm{ETCO}_{2}$ : The mean difference between $\mathrm{PaCO}_{2}$ and $\mathrm{ETCO}_{2}$ during Craniotomy at baseline, $1 \mathrm{hr}, 2 \mathrm{hr}, 3 \mathrm{hr}$ and $4 \mathrm{hr}$ are $3.66 \pm 1.15, \quad 3.20 \pm 1.31, \quad 3.26 \pm 1.73$, $3.52 \pm 1.49$ and $3.18 \pm 1.80 \mathrm{~mm}$ of $\mathrm{Hg}$ respectively. There is a significant correlation between $\mathrm{PaCO}_{2}$ and $\mathrm{ETCO}_{2}$ during Craniotomy with Pearson's correlation values at baseline, $1 \mathrm{hr}, 2 \mathrm{hr}, 3 \mathrm{hr}$ and 4hr are $0.799,0.522,0.582,0.439$ and 0.547 respectively. In this study a "P" value of $<0.05$ is considered significant with "P" values during Craniotomy at baseline, $1 \mathrm{hr}, 2 \mathrm{hr}, 3 \mathrm{hr}$ and $4 \mathrm{hr}$ are $0.000,0.003,0.001,0.015$ and 0.002 respectively showing significant correlation between $\mathrm{PaCO}_{2}$ and $\mathrm{ETCO}_{2}$ throughout Craniotomy. In our study we found the statistical significant correlation between $\mathrm{PaCO}_{2}$ and $\mathrm{ETCO}_{2}$ at $5 \%$ level of significance at baseline and after 1, 2, 3 and 4 hours during Craniotomy throughout the procedure in hemodynamically stable patients.

Garfield B. Russell et al in their study of 35 patients undergoing craniotomies studied correlation of PaCO2 and ETCO2 ${ }^{[16]}$. They found a significant positive correlation between $\mathrm{PaCO}_{2}$ and $\mathrm{PETCO}_{2}$ and $\mathrm{P}$ (a-ET)CO 2 , and $\mathrm{PaCO}_{2}$. Changes in the study population of $\mathrm{PaCO}_{2}$, and $\mathrm{PETCO}_{2}$ correlated statistically. in 1996 Kerr M E et al ${ }^{[17]}$ studied consecutive sample of 35 severe head-injured patients with a Glasgow Coma Scale score of $<$ or $=8$. In this study authors observed that end-tidal $\mathrm{CO}_{2}$ monitoring correlated well with $\mathrm{PaCO}_{2}$ in patients without respiratory complications or without spontaneous breathing. Fauzia khan et al ${ }^{[18]}$ In their study of 50 patients could show a moderate association between $\mathrm{PaCO}_{2}$ and $\mathrm{ETCO}_{2}$ in neurosurgical patients undergoing craniotomy. Similar results were found in studies conducted by Husaini et al ${ }^{[19]}$ and Lee et al ${ }^{[20]}$ in their studies. Table below shows the comparison between different studies which studied the correlation between $\mathrm{PaCO}_{2}$ and $\mathrm{ETCO}_{2}$ during craniotomy (Table 5).

Table 5: Correlation between $\mathrm{PaCO} 2$ and $\mathrm{ETCO} 2$ during craniotomy in other studies

\begin{tabular}{|c|c|c|c|c|c|}
\hline Author & $\begin{array}{l}\text { No Of } \\
\text { Patients }\end{array}$ & $\begin{array}{l}\mathrm{P}(\mathrm{a}-\mathrm{ET}) \mathrm{CO2} \\
\text { (mean) mm of } \\
\mathrm{Hg}\end{array}$ & $\begin{array}{l}\text { Correlation } \\
\text { coefficient }\end{array}$ & P Value & Correlation \\
\hline Garfield B Russel et al (1995) & 35 & $7.2 \pm 3.3$ & 0.632 & $<0.05$ & Significant \\
\hline Fauzia Khan et al (2007) & 50 & $4.09 \pm 3.0$ & 0.496 & & Moderate correlation \\
\hline $\begin{array}{l}\text { Husaini et al (2008) } \\
1.10 \text { min after induction. } \\
\text { 2. Prior to Dural Incision. } \\
\text { 3. Start of dural closure }\end{array}$ & 35 & $\begin{array}{l}3.84 \pm 2.13 \\
4.85 \pm 5.78 \\
3.91 \pm 2.33\end{array}$ & $\begin{array}{l}0.571 \\
0.559 \\
0.629\end{array}$ & & $\begin{array}{c}\text { Significant Significant } \\
\text { Significant }\end{array}$ \\
\hline Lee $S$ W et al (2009) & 66 & $\begin{array}{c}\text { Considered } \\
\text { normal is }-5 \text { to } 5\end{array}$ & 0.666 & $<0.001$ & Significant \\
\hline
\end{tabular}

Our study showed that $\mathrm{ETCO}_{2}$ is a measure for the $\mathrm{PaCO}_{2}$ in neurosurgical patients undergoing craniotomy which was consistent with the studies mentioned above. Thus we conclude that the End tidal Carbon dioxide $\left(\mathrm{ETCO}_{2}\right)$ reflects Arterial partial pressure of Carbon dioxide $\left(\mathrm{PaCO}_{2}\right)$ with a statistically significant accuracy and thus can be used as measure for $\mathrm{PaCO}_{2}$. These conclusions are similar to various studies

\section{Conclusion}

In this prospective observational study of 30 patients, in the age group of 18- 60 years, under 


\section{JMSCR Vol||05||Issue||03||Page 18525-18533||March}

ASA I and II category, we observed significant correlation in between $\mathrm{PaCO}_{2}$ and $\mathrm{ETCO}_{2}$ during elective neurosurgery patients undergoing craniotomy under general anaesthesia.

Thus, this study shows that end-tidal $\mathrm{CO}_{2}$ $\left(\mathrm{ETCO}_{2}\right)$ reflects arterial $\mathrm{CO}_{2}$ with acceptable accuracy. So, we can rely on Capnometry for $\mathrm{CO}_{2}$ measurement over arterial $\mathrm{CO}_{2}$ measurement in neurosurgical patients which is simple, continuous and non-invasive Carbon dioxide monitoring as compared to arterial Carbon dioxide monitoring which is expensive, intermittent and includes invasive intervention.

\section{Conflict Of interest: None}

\section{References}

1. Benallal H, Busso T. Analysis of end-tidal and arterial $\mathrm{PCO} 2$ gradients using a breathing model. Eur J Appl Physiol 2000; 83:402-8.

2. Nunn JF: In Nunn JF Applied Respiratory Physiology. 3rd edition London: Butterworths, 1987, pp 207-34.

3. Russell GB, Graybeal JM. End-tidal carbon dioxide as an indicator of arterial carbon dioxide in neurointensive care patients. J Neurosurg Anesth 1992; 4:245-9.

4. Isert PR. Arterial to end-tidal $\mathrm{CO} 2$ difference during neurosurgical procedures. Can J Anesth 1996; 43:196-7.

5. McCarter T, Shaik Z, Scarfo K, Thompson LJ. Capnography Monitoring Enhances Safety of Postoperative Patient-Controlled Analgesia. American Health \& Drug Benefits. 2008;1(5):28-35.

6. Casati A, Salvo I, Torri G, Calderini E. Arterial to end-tidal carbon dioxide gradient and physiological dead space monitoring during general anaesthesia: effects of patients' position. Minerva Anestesiol. 1997 Jun;63(6):177-82.

7. Gelb AW, Craen RA, Rao GS, Reddy KR, Megyesi J, Mohanty B, Dash HH, Choi KC, Chan MT. Does hyperventilation improve operating condition during supratentorial craniotomy? A multicenter randomized crossover trial. Anesth Analg. 2008 Feb;106(2):585-94.

8. Yoon S, Zuccarello M, Rapoport RM. $\mathrm{pCO}_{2}$ and $\mathrm{pH}$ regulation of cerebral blood flow. Frontiers in Physiology. 2012;3:365.

9. Puppo C, Fariña G, López FL, Caragna E, Biestro A. Cerebral $\mathrm{CO} 2$ reactivity in severe head injury. A transcranial Doppler study. Acta Neurochir Suppl. 2008; 102:171-5.

10. Rangel-Castillo L, Gopinath S, Robertson CS. Management of Intracranial Hypertension. Neurologic clinics. 2008;26(2):521541.

11. Dennis LJ, Mayer SA. Diagnosis and management of increased intracranial pressure. Neurol India. 2001 Jun;49 Suppl 1:S37-50.

12. Agus MS, Alexander JL, Mantell PA. Continuous non-invasive end-tidal $\mathrm{CO} 2$ monitoring in pediatric inpatients with diabetic ketoacidosis. Pediatr Diabetes. 2006 Aug;7(4):196-200.

13. Owen R, Castle N. $\mathrm{EtCO}_{2}$ : the key to effective prehospital ventilation. Emergency Medicine Journal: EMJ. 2006;23 (7):578-579.

14. Xu A-J, He Z-G, Xia X-H, Xiang H-B. Anesthetic management for craniotomy in a patient with massive cerebellar infarction and severe aortic stenosis: a case report. International Journal of Clinical and Experimental Medicine. 2015;8(7): 11534-11538.

15. Ferber J, Juniewicz HM, LechowiczGłogowska EB, Pieniek R, Wroński J. Arterialto end-tidal carbon dioxide difference during craniotomy in severely head-injured patients. Folia Med Cracov. 2001;42(4):141-52.

16. Garfield B. Russell, MD, FRCPC, and John M. Graybeal Anesth Analg 1995;81:806-10. 


\section{JMSCR Vol||05||Issue||03||Page 18525-18533||March}

17. Kerr ME, Zempsky J, Sereika S, Orndoff P, Rudy EB, "Relationship between arterial carbon dioxide and end-tidal carbon dioxide in mechanically ventilated adults with severe head trauma." Crit Care Med. 1996 May; 24(5):785-90.

18. Fauzia Khan, Mueenullah Khan, Shemila Abbasi, Department of Anaesthesia, Aga Khan University, Karachi, studied "Arterial to End-Tidal Carbon Dioxide Difference in Neurosurgical Patients undergoing Craniotomy: A Review of Practice". JPMA 57;446:2007.

19. Husaini J , Y C Choy, "End-tidal to arterial carbon dioxide partial pressure difference during craniotomy in anaesthetised patients." Med J Malaysia , 2008 Dec;63(5):384-7.

20. Lee SW, Hong YS, Han C, Kim SJ, Moon SW, Shin JH, Baek KJ, "Concordance of end-tidal carbon dioxide and arterial carbon dioxide in severe traumatic brain injury." J Trauma 2009 Sep;67(3):526-30. 